Pediat. Res. 1: 461-469 (1967)

Mosaicism

tetraploidy

DNA

microcephaly dermatoglyphics

chromosomes

immunoglobulins

\title{
Tetraploid-Diploid Mosaicism in a Surviving Infant
}

\author{
Gertrude KohN ${ }^{[19]}$, B.H. Mayall, M.E. Miller and W.J. Mellman \\ Departments of Pediatrics and Radiology, University of Pennsylvania School of Medicine, \\ and The Children's Hospital of Philadelphia, Philadelphia, Pennsylvania, USA
}

\section{Extract}

Although tetraploidy and tetraploid-diploid mosaicism has been well documented in studies of aborted human fetuses, no living case has been reported. This report concerns a male infant with tetraploiddiploid mosaicism who survived for 36 weeks. Because the peripheral blood cells of this infant displayed gross differences both in cell size and in DNA content, it was possible to establish that the tetraploidy observed in cultured cells was a true reflection of in vivo mosaicism.

The propositus was born on December 6, 1965, after a 42-week gestation notable for a paucity of fetal movement. Birth weight was $1.7 \mathrm{~kg}$, length $40.6 \mathrm{~cm}$ and head circumference $25.4 \mathrm{~cm}$. He presented with multiple congenital anomalies. Peripheral blood smears appeared to contain two populations of neutrophilic granulocytes that differed in overall size.

Immunological assessment gave the following results: 1. Serum immunoelectrophoresis performed at the ages of 4, 10 and 14 weeks showed qualitatively normal immunoglobulins. 2 . Normal antibody responses were obtained to type I polio and to typhoid-paratyphoid vaccines given at age 10 weeks. 3. Normal delayed hypersensitivity was obtained following stimulation with 2,4-dinitrofluorobenzene at the age of 12 weeks. There was a normal plasma growth hormone response to insulin-induced hypoglycemia at 12 weeks of age.

Many of the cells in follicular centers of the spleen and lymph nodes were pale, and the lymphocytes surrounding them were bizarre, being unusually large and hyperchromatic. The histologic architecture was preserved and cortico-medullary differentiation maintained.

Tetraploid-diploid mosaicism was found in ten short-term cultures of peripheral blood leukocytes obtained over a seven-month period. The average proportion of tetraploid cells was $69 \%$ (range 64 to $77 \%$ ).

Chromosomal analysis of six different primary fibroblast cultures, including that derived from the postmortem lung, were diploid in number and euploid in karyotype.

Peripheral blood smears appeared to have two populations of neutrophilic granulocytes which differed from one another in their overall size. The distributions of cell diameters from all of the subject's smears showed highly significant positive skewing, in contrast to the more symmetrical distributions from the control smears.

Analysis of bimodality, using a computer, indicated the presence of two normally distributed subpopulations. The results generated are given in table IV.

Cytophotometric measurements of cellular DNA content can be used to analyze tetraploid-diploid mosaicism, since tetraploid cells have twice as much DNA as diploid cells. The large cells in peripheral blood from the subject had 2.01 times the stain content of his normal appearing cells, and 
1.91 times that of the control. In order to estimate the incidence of tetraploidy among the subject's leukocytes, measurements were made on randomly selected cells and gave the results shown in table V.

In the infant reported here, tetraploid-diploid mosaicism was evident only in the hematopoietic and lymphatic cells. Fibroblast cultures from skin, muscle and lung tissue were diploid. Different cell types showed different proportions of tetraploid cells, but these proportions were maintained throughout life. No functional abnormality was found in these tissues.

\section{Speculation}

The marked growth disorder and congenital malformations of the infant discussed in this report indicate that there must have been severe disturbances present in other tissues. Perhaps tetraploid cells also occurred in those other tissues during the early stages of embryogenesis, but these cells were relatively deficient in their ability to undergo embryogenic differentiation and were gradually eliminated. The remaining diploid cells may have then been unable to compensate for the defunct tetraploid cells, thus leading to defects of organ development and of subsequent growth.

\section{Introduction}

Although tetraploidy and tetraploid-diploid mosaicism have been well documented in studies of aborted human fetuses [4], no living case has been reported. We present here a male infant with tetraploid-diploid mosaicism who survived for 36 weeks.

Ghromosome mosaicism is said to exist when two or more karyotypically distinct populations are found in cells from a single individual. Because the peripheral blood cells of this infant displayed gross differences both in cell size and in DNA content, it was possible to establish that the tetraploidy observed in his cultured cel's was a true reflection of in vivo mosaicism.

\section{Case Report}

The propositus was born on December 6, 1965, after a 42-week gestation notable for a paucity of fetal movement. The infant cried spontaneously. Birth weight was $1.7 \mathrm{~kg}$, length $40.6 \mathrm{~cm}$ and head circumference $25.4 \mathrm{~cm}$. The placenta was small but had no gross pathology.

The parents were of European origin and were unrelated. The father was 30 years old and had suffered four years earlier from infectious hepatitis. The mother was 29 years old and had previously had one ectopic and five normal pregnancies. She had taken no medications prior to conception of the propositus, but did take oral contraceptive pills (Enovid) for several days after the first missed menstrual period.

When first seen at the Children's Hospital of Philadelphia, the infant was nine days old. He presented with multiple congenital anomalies (fig. 1). The head was microcephalic, the fontanelles were closed and the sutures overriding. The pupils were widely dilated and unreactive to light. The left pupil was irregular. Corneal opacification was noted in the left eye and aphakia in the right eye. Corneal reflexes were absent and there was bilateral retinal detachment. The ears were normally placed and not malformed. The nose was prominent. The mouth was small and micrognathia was marked. The palate was normal. The chest was normally shaped, heart sounds were regular, and there were no murmurs. The external genitalia were normal and both testes were descended.

The elbows could be extended to $160^{\circ}$. The hand posture was normal but the fingers were short with only two phalanges. A simian line was present on the right palm. There was limited abduction of the right hip and the right leg was $2 \mathrm{~cm}$ shorter than the left leg. The right foot was severely malformed and had only the great toe and one other rudimentary toe. The left foot had syndactylism between the second and third toe and between the fourth and fifth toe.

The Moro reflex was absent. Focal seizures involving predominantly the left side were noted soon after birth. These occurred daily and persisted throughout life. Two days after admission, a rapidly progressive proptosis of the left eye was noted. This proved to be an intraocular $E$. coli abscess which drained spontaneously and resulted in marked enophthalmus.

The infant's weight decreased until four weeks of age when it stabilized at about $1.4 \mathrm{~kg}$. He maintained this weight and, despite an adequate caloric intake, never grew in size nor gained weight. From May 5, 1966, to August 17, 1966, he was cared for in a nursing home where he died suddenly and unexpectedly when 36 weeks old. 


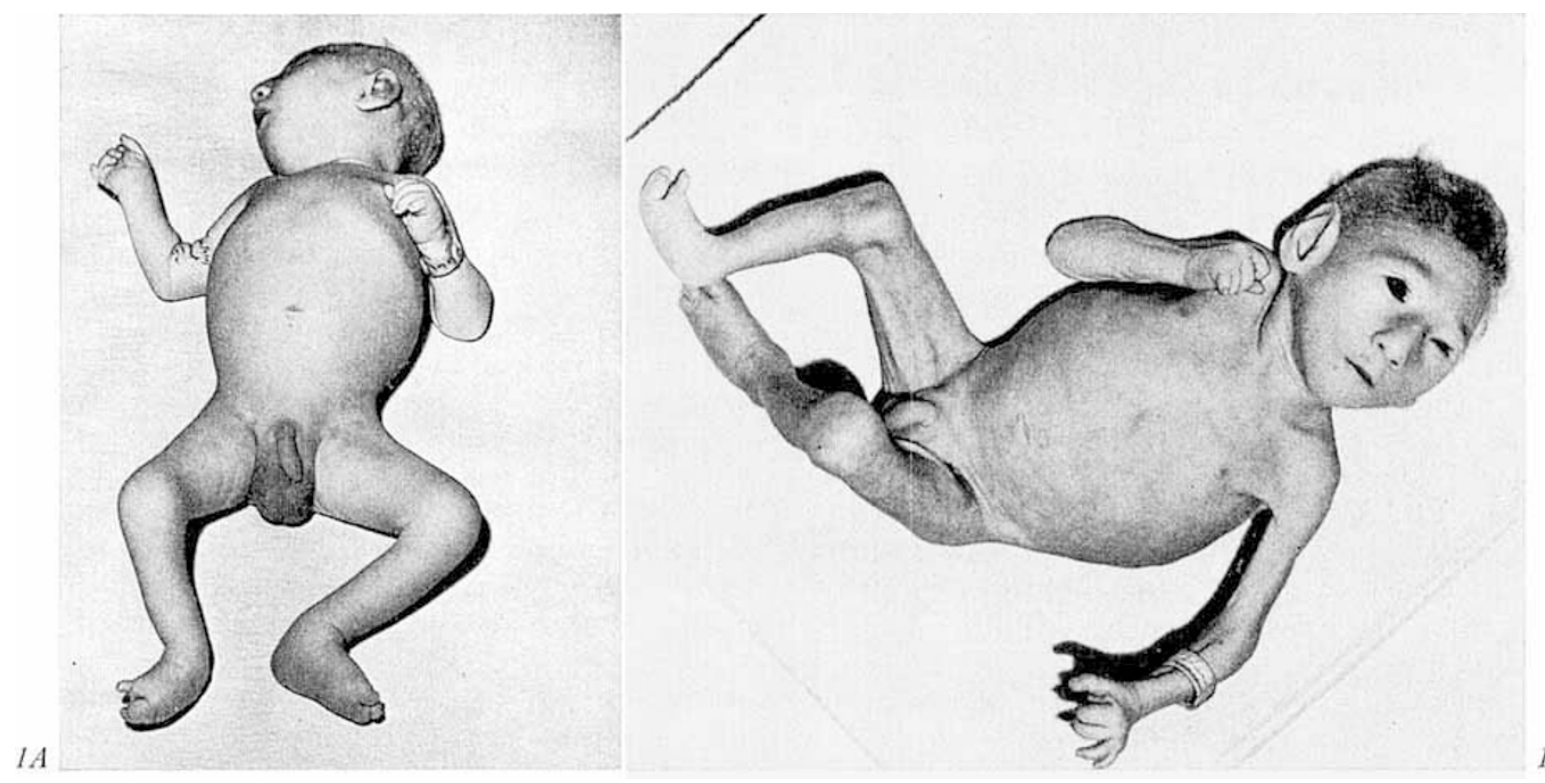

Fig.1. Propositus, aged A. six weeks and B. eight months.

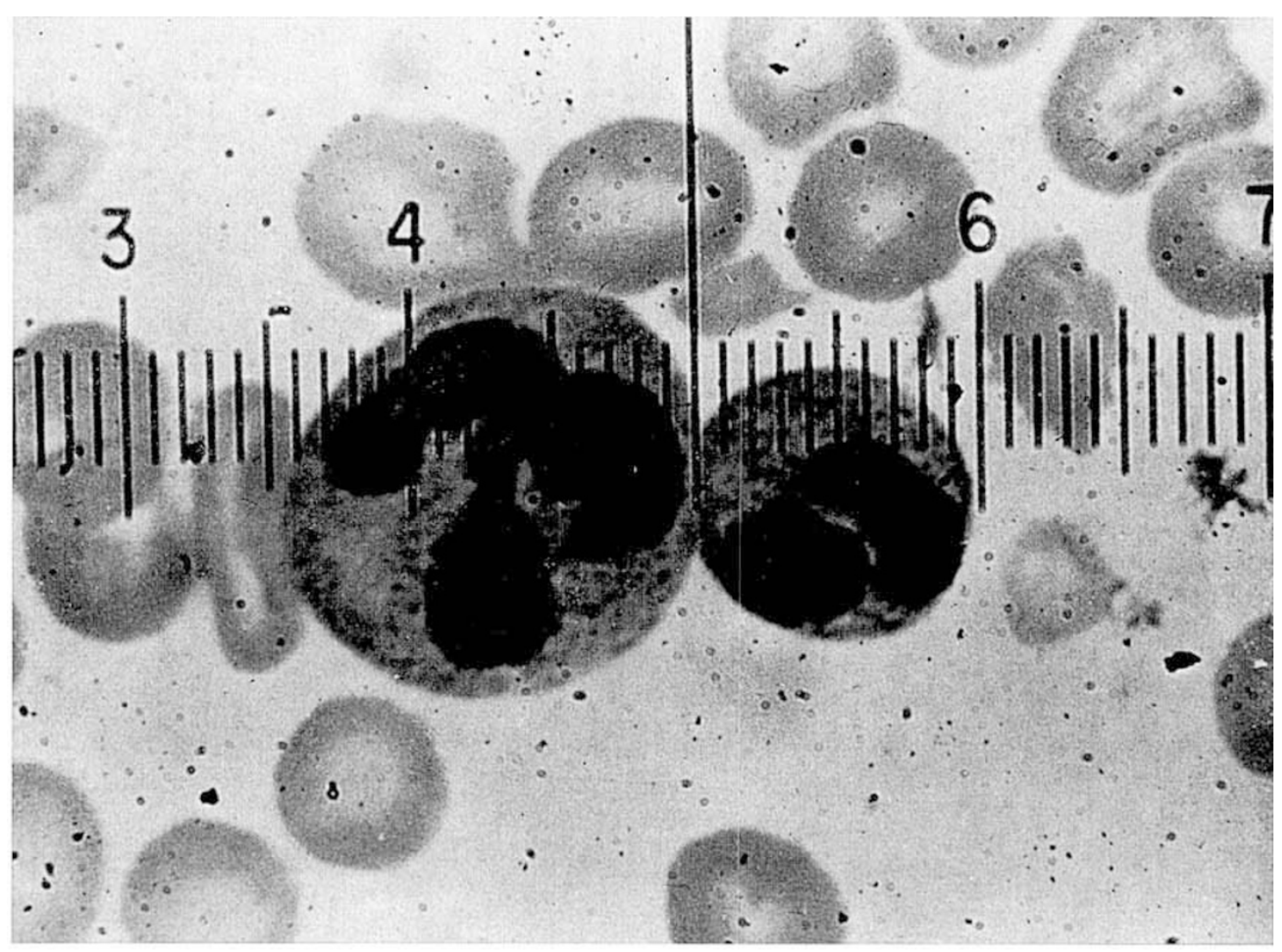

Fig. 2. Neutrophilic granulocytes from a peripheral blood smear. The smaller cell is comparable in size to cells from normal smears. Note the morphological normality of the large cell, apart from its size. 


\section{Laboratory Data}

Peripheral blood smears appeared to contain two populations of neutrophilic granulocytes that differed in overall size (fig. 2). Otherwise, there were no unusual hematological findings. There was a normal neutrophil response to the $E$. coli infection of the orbit.

Immunological assessment gave the following results: 1. Serum immunoelectrophoresis performed at the ages of 4, 10 and 14 weeks showed qualitatively normal immunoglobulins. 2. Normal antibody responses were obtained to type I polio and to typhoid-paratyphoid vaccines given at age 10 weeks. 3 . Normal delayed hypersensitivity was obtained following stimulation with 2,4-dinitrofluorobenzene at the age of 12 weeks.

There was a normal plasma growth hormone response [15] to insulin-induced hypoglycemia at the age of 12 weeks.

Blood groupings of the parents and infant were normally distributed (see table I). No sex chromatin bodies were observed in buccal mucosal cells or peripheral blood polymorphonuclear leukocytes.

An EEG taken when the infant was ten days old was abnormal, showing repetitive high-voltage electrical discharges.

\section{Radiological Studies}

$\mathrm{X}$-rays of the skull and a right brachial arteriogram were consistent with a decrease in brain size. The right vertebral artery was hypoplastic. The chest showed normal lung fields and isolated dextrocardia. An angiocardiogram revealed no other cardiac abnormalities. A flat plate of the abdomen was normal, with the liver on the right side. An intravenous pyelogram showed good dye excretion although the kidneys could not be visualized. Skeletal films showed multiple anomalies. All fingers had only two phalanges and there was a synostosis of the proximal three quarters of the fourth and fifth metacarpals of the right hand. The pelvis was small with shallow acetabula. The right femur and the right tibia were short and there was no right fibula. The left foot had three tarsal and four metatarsal bones. The first three metatarsals had single proximal and distal phalanges while the fourth metatarsal had a proximal and two distal phalanges. There were no middle phalanges. The right foot had one tarsal and two metatarsal bones with two rudimentary bones in the great toe and a single rudimentary bone in the only other toe.

\section{Dermatoglyphics}

A triradius was present at the junction of the proximal and middle third of each palm. There were narrow ulner loop patterns on digits I and III of the right hand and I, II, IV and V of the left hand. A tented arch pattern was present in the right hand on digitis II and IV, and in the left hand on digit III. No pattern was discernible on digit $\mathrm{V}$ of the right hand.

\section{Autopsy Findings}

All internal organs were normal to both gross and microscopic examination with the exception of the brain, eyes, heart, skeletal system and reticulo-endothelial system. The heart was normal, apart from the dextrocardia, while the skeletal system showed pathology consistent with the X-ray findings. A detailed account of the brain and eye pathology will be reported elsewhere.

All lymph nodes (cervical, mediastinal, mesenteric and small bowel lymphoid tissue) and the spleen showed follicles containing pale, small germinal centers. Many of the cells in these centers and the lymphocytes surrounding them were bizarre, being unusually large and hyperchromatic. Nevertheless, the histologic architecture of these organs was preserved. In the thymus, the lymphocytes showed nuclear atypism, resulting in a pleomorphic population not unlike that seen in the lymph nodes and the spleen. Again, histologic architecture was preserved and cortico-medullary differentiation maintained.

\section{Chromosome Analysis}

Ten short-term cultures of peripheral blood leukocytes [10] were obtained over a seven-month period (table II). Tetraploid-diploid mosaicism was found in all cultures. The average proportion of tetraploid cells was $69 \%$ (range 64 to $77 \%$ ). Analysis of the diploid cells revealed them to be euploid with $\mathrm{XY}$ sex chromosomes. The tetraploid cells had a full double complement of chromosomes with XXYY sex chromosomes (fig. 3).

Table I. Blood groupings of the subject and his parents

\begin{tabular}{|c|c|c|c|c|c|c|c|c|c|c|c|c|c|c|c|c|c|c|c|c|}
\hline & A & $\mathrm{A}_{1}$ & B & G & $\mathrm{D}$ & $\mathrm{E}$ & c & e & $\mathrm{C}^{\mathrm{w}}$ & $\mathrm{P}$ & $\mathrm{K}$ & $\mathrm{K} \mathrm{p}^{\mathrm{a}}$ & ${ }^{\mathrm{a}} \mathrm{K} \mathrm{p}^{\mathrm{b}}$ & $\mathrm{M}$ & $\mathrm{N}$ & $\mathrm{S}$ & s & $\mathrm{Lu}^{\mathrm{a}}$ & $F y^{a}$ & $\mathrm{Jk}^{\mathrm{a}}$ \\
\hline Propositus & + & - & - & + & + & + & + & + & - & + & 一 & - & + & + & + & - & + & - & - & + \\
\hline Father & + & + & - & + & + & + & + & + & - & + & - & - & + & + & + & - & + & 一 & - & + \\
\hline Mother & - & 一 & - & + & + & + & + & + & - & + & - & - & + & + & + & 一 & + & - & - & + \\
\hline
\end{tabular}




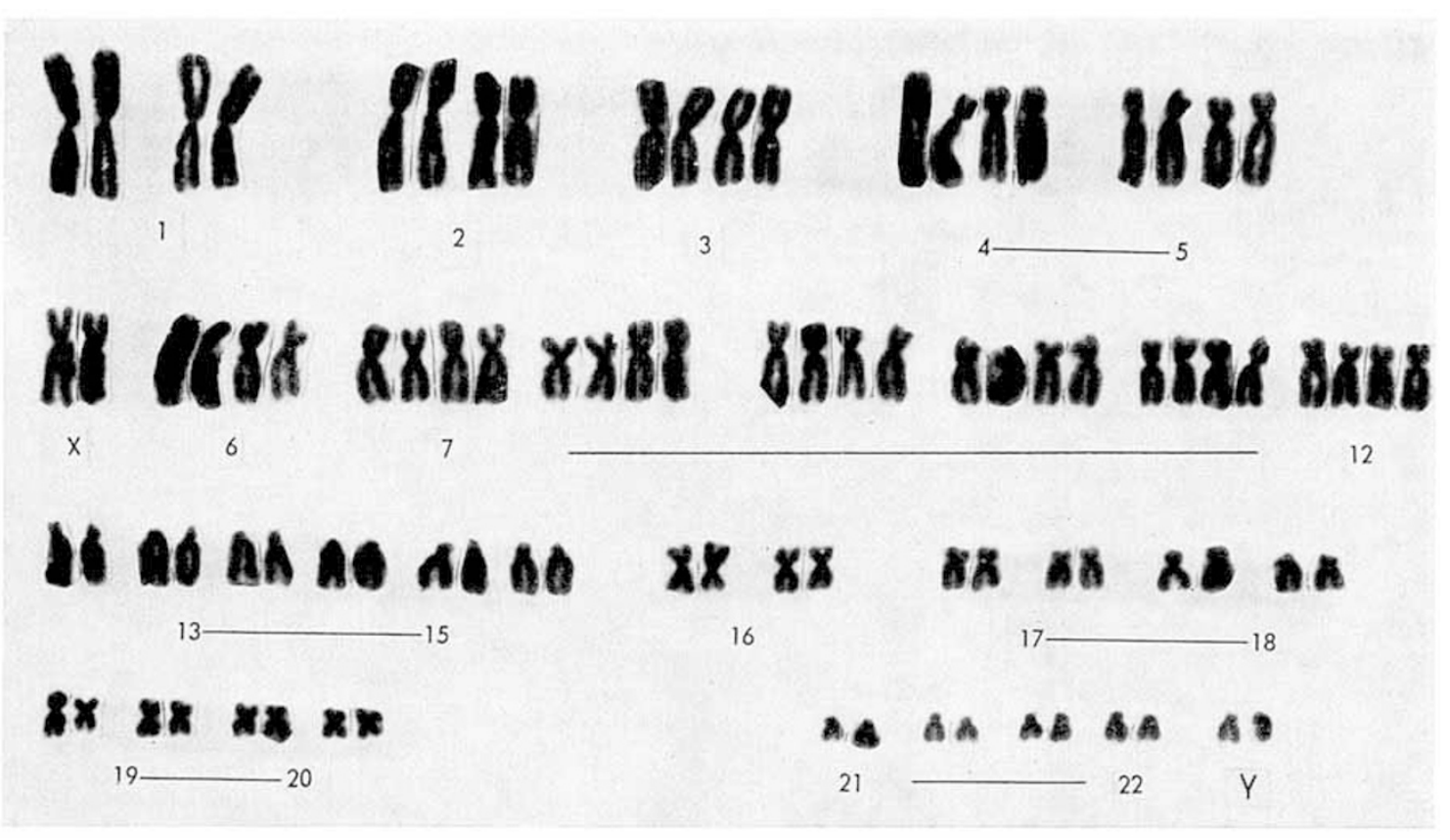

Fig. 3. Karyotype of a tetraploid cell from a culture of peripheral leukocytes.

Table II. Chromosome analysis from short-term cultures of peripheral blood

\begin{tabular}{lllll}
\hline Date & $\begin{array}{l}\text { Numbers of } \\
\text { cells counted }\end{array}$ & Diploid & Tetraploid & $\begin{array}{l}\text { Percent } \\
\text { tetraploid }\end{array}$ \\
\hline 21 December 1965 & 100 & 31 & 69 & 69 \\
7 January 1966 & 200 & 51 & 149 & $741 / 2$ \\
7 January 1966 & 200 & 66 & 134 & 67 \\
17 January 1966 & 200 & 62 & 138 & 69 \\
7 February 1966 & 200 & 67 & 133 & $661 / 2$ \\
14 February 1966 & 200 & 63 & 137 & $681 / 2$ \\
7 March 1966 & 200 & 59 & 141 & $701 / 2$ \\
18 March 1966 & 200 & 61 & 139 & $691 / 2$ \\
25 April 1966 & 200 & 46 & 154 & 77 \\
27 July 1966 & 100 & 36 & 64 & 64 \\
\hline
\end{tabular}

Anaphase preparations from several leukocyte cultures revealed no abnormalities in either the diploid or tetraploid cells.

Cultures (pulsed for 20 minutes with $\mathrm{H}^{3}$-thymidine and harvested four hours later) were examined autoradiographically [13] and no late replicating chromosomes were seen in either diploid or tetraploid metaphases.

Bone Marrow Preparations

An unusually high percentage of metaphases from several preparations of an iliac bone marrow aspirate [16] were not analyzable. Of the analyzable metaphases, 275 were diploid and 2 were tetraploid.

Skin, Muscle and Lung Fibroblast Cultures

Fibroblast-like cultures were established from a muscle biopsy obtained at seven weeks and skin biopsies obtained at six and fifteen weeks of life [9]. Most of the biopsies explanted normally and could be examined karyologically, but failed to subpassage following trypsinization. None could be established as cell lines. 
However, lung tissue obtained at autopsy was successfully established as a fibroblast-like line and has subpassaged normally. Chromosomal analysis of six different primary fibroblast cultures, including that derived from the postmortem lung, were diploid in number and euploid in karyotype.

\section{Peripheral Blood Neutrophil Sizes}

Peripheral blood smears appeared to have two populations of neutrophilic granulocytes which differed from one another in their overall size (fig. 2). In order to quantitate this observation, cell diameters were measured using a calibrated ocular. Only perfectly round neutrophils were chosen for measurement.

Five smears of the subject's peripheral blood, obtained over a six-week period, were analyzed and smears from the blood of ten normal infants of approximately the same age were used as controls. Twohundred neutrophils were chosen from each smear. The measurements and their statistics are given in table III. The distributions of cell diameters from all of the subject's smears show highly significant positive skewing, in contrast to the more symmetrical distributions from the control smears.

The skewing of the subject's cell diameters is suggestive of a heterogeneous population of cells. These distributions were examined further using a computer analysis of bimodality devised and kindly supplied by Mrs. J.M.S. Prewitt. In this analysis, the data are assumed to come from two normally distributed subpopulations. The subpopulations are present in unknown proportions, and they each have unknown means and common but unknown variances. The analysis determines the statistics of those two subpopulations which give, when combined, the best fit of the data.

When the data on the subject's neutrophils were subjected to this analysis, the results given in table IV were generated. These show considerable variation in the proportions of the two subpopulations. But when the means of the two subpopulations are compared, it is found that the ratios show little variation and have an average value of 1.39 . This is close to 1.41 , the ratio expected in tetraploid-diploid mosaicism if it is assumed that tetraploid cells have twice the volume of diploid cells, but are flattened to discs of the same thickness.

Table III. Diameters of neutrophilic granulocytes. The statistics are given as the measures of skewness and of kurtosis and are the observed values of the skew and kurtosis normalized through dividing respectively by the standard deviations of the skew and kurtosis expected if the populations had been normally distributed

\begin{tabular}{|c|c|c|c|c|c|c|c|c|c|c|c|c|c|c|}
\hline & \multicolumn{10}{|c|}{ Measurements in $\mu$} & \multicolumn{4}{|c|}{ Statistics } \\
\hline & 8.3 & 9.5 & 10.7 & 11.9 & 13.1 & 14.3 & 15.5 & 16.6 & 17.8 & 19.0 & Mean & $\begin{array}{l}\text { Stand- } \\
\text { ard } \\
\text { devia- } \\
\text { tion }\end{array}$ & $\begin{array}{l}\text { Skew } \\
\text { measure }\end{array}$ & $\begin{array}{l}\text { Kurtosis } \\
\text { measure }\end{array}$ \\
\hline \multicolumn{15}{|l|}{ Control infants } \\
\hline 1 & & 1 & 47 & 121 & 27 & 4 & & & & & 11.82 & 0.82 & 2.18 & 2.06 \\
\hline 2 & 27 & 137 & 33 & 3 & & & & . & & & 9.57 & 0.72 & 2.36 & 3.18 \\
\hline 3 & 2 & 24 & 60 & 103 & 11 & & & & & & 11.28 & 0.97 & -3.46 & 0.10 \\
\hline 4 & 2 & 36 & 77 & 74 & 9 & 2 & & & & & 11.05 & 1.06 & 0.35 & 0.04 \\
\hline 5 & 2 & 28 & 51 & 88 & 26 & 5 & & & & & 11.44 & 1.19 & -0.71 & -0.43 \\
\hline 6 & & 3 & 41 & 132 & 23 & 1 & & & & & 11.77 & 0.75 & -0.99 & 2.96 \\
\hline 7 & 20 & 82 & 71 & 26 & 1 & & & & & & 10.14 & 1.03 & 0.98 & -1.28 \\
\hline 8 & 1 & 7 & 41 & 119 & 30 & 2 & & & & & 11.76 & 0.90 & -2.50 & 3.70 \\
\hline 9 & 18 & 80 & 96 & 6 & & & & & & & 10.04 & 0.84 & -2.05 & -0.95 \\
\hline 10 & 1 & 28 & 65 & 90 & 13 & 3 & & & & & 11.27 & 1.06 & -0.19 & 0.29 \\
\hline \multicolumn{15}{|l|}{ Subject } \\
\hline 5 January 1966 & & 16 & 28 & 105 & 24 & 9 & 7 & 2 & 8 & 1 & 12.24 & 1.82 & 8.59 & 8.35 \\
\hline 14 January 1966 & 23 & 66 & 37 & 35 & 18 & 14 & 4 & 1 & 2 & & 10.90 & 1.98 & 5.36 & 1.87 \\
\hline 25 January 1966 & 68 & 70 & 37 & 20 & 3 & 2 & & & & & 9.66 & 1.32 & 5.41 & 1.76 \\
\hline 4 February 1966 & & & 2 & 97 & 67 & 26 & 4 & 3 & 1 & & 12.77 & 1.12 & 8.17 & 7.90 \\
\hline 18 February 1966 & & 95 & 70 & 26 & 6 & 0 & 1 & 1 & 1 & & 10.45 & 1.23 & 13.61 & 26.83 \\
\hline
\end{tabular}


Table IV. Parameters of the subpopulations that give, when combined, the best fit to measured diameters of the patient's neutrophilic granulocytes

\begin{tabular}{lcccc}
\hline & \multicolumn{2}{c}{ Means } & Ratio means & $\begin{array}{r}\text { Percentage of } \\
\text { population II }\end{array}$ \\
\cline { 2 - 3 } & Population I & Population II & & \\
\hline Subject & & & 1.44 & 7.9 \\
5 January 1966 & 11.82 & 17.07 & 1.42 & 15.3 \\
14 January 1966 & 10.24 & 14.55 & 1.31 & 15.7 \\
25 January 1966 & 9.20 & 12.07 & 1.25 & 7.8 \\
4 February 1966 & 12.52 & 15.71 & 1.53 & 2.9 \\
18 February 1966 & 10.29 & 15.77 & & \\
\hline
\end{tabular}

\section{Cytophotometric Confirmation of Tetraploid-Diploid Mosaicism}

Gytophotometric measurements of cellular DNA content can be used to analyze tetraploid-diploid mosaicism, since tetraploid cells have twice as much DNA as diploid cells. However, only certain tissues are suitable for analysis. Most tissues have cells that are actively replicating and which may have either doubled their DNA content, or else have some intermediate value; other tissues, such as liver, normally show some polyploidy. Hence the interpretation of measurements is unambiguous only for those cells from normally diploid tissue that are at a defined stage in the cell cycle. These criteria are met by cells in metaphase or by cells, such as the leukocytes in the peripheral blood, that are nonproliferating.

Slides were prepared from peripheral blood of the subject and of a female infant control. The blood was sedimented and the leukocyte-rich serum used. Smears were made with cells from the subject on one half of the slide and from the control on the other half. These slides were fixed in absolute ethanol and then stained with gallocyanin-chrome alum after ribonuclease treatment. The relative cellular DNA stain content was measured, using a scanning digital cytophotometer $[3,12]$.

Measurements were made on 15 neutrophilic granulocytes chosen at random. The subject's smear was then surveyed further for abnormally large neutrophils, and a cluster of four such cells was found. The large cells from the subject had 2.01 times the stain content of his normal appearing cells and 1.91 times that of the control. A difference of $5 \%$ between the means of the control and the subject's normal cells is similar to that previously found between male and female leukocytes [11].

In order to estimate the incidence of tetraploidy amongst the subject's leukocytes, measurements were made on randomly selected cells and gave the results
Table $V$. The incidence of cells with twice the normal DNA stain content. The value for control leukocytes is designated $2 \mathrm{c}$

\begin{tabular}{lrl}
\hline & $4 \mathrm{c}: 2 \mathrm{c}$ & Percent 4c \\
\hline Peripheral blood & & \\
$\quad$ Neutrophils & $3: 97$ & 3.0 \\
$\quad$ Eosinophils & $3: 25$ & 10.7 \\
$\quad$ Nongranulocytes & $44: 56$ & 44.0 \\
& $8 \mathrm{c}: 4 \mathrm{c}$ & Percent $8 \mathrm{c}$ \\
Bone marrow & & \\
$\quad$ Metaphase cells & $3: 22$ & 12.0 \\
\hline
\end{tabular}

shown in table V. No attempt was made to differentiate between monocytes and lymphocytes in this preparation. Of these cells, those with the double stain content appeared similar to small lymphocytes, apart from their greater size.

Measurements were also made on cells from an imprint of an inguinal lymph node obtained at biopsy and from a bone marrow smear. Of 50 lymph node cells, nine had twice the stain content of control leukocytes and one had an intermediate value. Since some of the cells in a lymph node are normally synthesizing DNA and dividing, these results are difficult to interpret. However, the high proportion of large cells, especially when considered in conjunction with the blood lymphocyte measurements, suggests that many of them were tetraploid. On the bone marrow smear, 60 interphase cells were measured. Twenty of these had a high stain content, but as this is a rapidly dividing tissue, interpretation is again difficult. However, when 25 metaphase cells were chosen from the bone marrow smear, 22 cells had the stain content expected for diploid metaphases, being twice that of the control leukocytes; but 3 cells had four times the control value and were presumably tetraploid. 


\section{Discussion}

In the human, polyploidy is a rare occurrence. True triploidy and tetraploidy have only been observed in aborted specimens. Triploid-diploid mosaicism has been reported in three individuals who have survived fetal life $[2,5,6]$. In these subjects, mosaicism was found only in fibroblast cultures derived from skin or fascia lata but not in leukocyte and bone marrow cul tures. In the infant reported here, tetraploid-diploid mosaicism was evident only in the hematopoietic and lymphatic cells. Fibroblast cultures from skin, muscle and lung tissue were diploid. It is possible that some tetraploid cells were present in the original biopsy specimens but did not divide in culture. The reason for the failure of the skin and muscle cultures to subpassage is obscure, but this failure may be the in vitro expression of the total absence of growth of the propositus; an absence that, in the presence of normal growth hormone values, would suggest an end organ defect.

Polyploidy is not rare in plants and triploidy, in particular, has been found in animals. It was noted by MÜNTZING [14] in plants and by FrankHauser [7] and Böök [1] in animals that polyploid cells are larger than diploid. However, in contrast to most experiences with plants, the organ and body sizes of triploid animals were usually not larger than normal as there was a concomitant decrease in the total number of cells [7].

In the infant we have described, tetraploid-diploid cells were found only in hematopoietic and lymphatic tissue. Different cell types showed different proportions of tetraploid cells, but these proportions were maintained throughout life. Furthermore, no functional abnormality was found in these tissues. This suggests that the tetraploid cells in these tissues had the same mitotic potential as the diploid cells and that the presence of mosaicism did not interfere with the tissue function. However, the marked growth disorder and congenital malformations of the infant indicate that there must have been severe disturbances present in other tissues. Perhaps tetraploid cells also occurred in these other tissues during the early stages of embryogenesis, but these cells were relatively deficient in their ability to undergo embryogenic differentiation and were gradually eliminated. The remaining diploid cells may have then been unable to compensate for the defunct tetraploid cells, thus leading to defects of organ development and of subsequent growth. The growth disorder characteristic of $45, \mathrm{X}$ individuals with Turner's syndrome has been explained by an analogous hypothesis in which a functional mosaicism is postulated with the single $\mathrm{X}$ chromosome inactive in a proportion of the cells [8]. While these hypotheses may not be correct, it remains reasonable, nonetheless, to suppose that the tetraploid-diploid mosaicism of the propositus caused the multiple congenital anomalies and both the in vivo and in vitro failure of growth.

\section{Summary}

A male infant is described in whom tetraploid-diploid mosaicism was demonstrated in both lymphoid and myeloid cells of the peripheral blood, but not in cultured fibroblasts of the skin, muscle and lung. The infant manifested multiple congenital anomalies and a severe degree of intrauterine and extrauterine growth failure. There was no evidence of growth from birth until death 36 weeks later, despite normal growth hormone.

Lymphoid tissue studied postmortem showed atypical cells which were, presumably, tetraploid. Nevertheless, all the tests for immunological competence were normal. There was also a normal neutrophilic response to infection.

This report of mosaicism illustrates a way in which measurements of cell diameters can be analyzed for heterogeneity. It also presents cytophotometry as a powerful adjunct to conventional cytogenetic techniques in the study of chromosomal disorders in which there is a net gain or loss of DNA. Cytophotometric measurement of nuclear DNA content is uniquely applicable to nondividing cells, and it avoids the hazards and potential artefacts of selection that may occur with cell culture.

\section{References and Notes}

1. Böök, J.A.: Triploidy in Triton Taeniatus Laur. Hereditas (Lund) 26: 107-114 (1940).

2. Böök, J.A.; Masterson, J.G. and Santesson, B. : Malformation syndrome associated with triploidy -further chromosome studies of the patient and his family. Acta Genet. Basel 12: 193-201 (1962).

3. Bostrom, R. C. and Holcomb, W. G.: CYDACA digital scanning cytophotometer. IEEE International Convention Record Part 9: 110-119 (1963).

4. CARR, D.H.: Chromosome studies in spontaneous abortions. Obstet. Gynec. (N.Y.) 26: 308-326 (1965).

5. Ellis, J. R.; Marshall, R.; Normand, I. G. S. and Penrose, L. S.: A girl with triploid cells. Nature (Lond.) 198: 411 (1963).

6. Ferrier, P.; Ferrier, S.; Stolder, G.; Bühler, E.; Bamatter, F. and Klein, D.: Congenital asymmetry associated with diploid-triploid mosaicism and large satellites. Lancet $i$ :80-82 (1964). 
7. FrankHAuser, G.: The effects of triploidy on cell size and organ size in salamanders. Genetics 24: 71 (1939).

8. Gartler, S.M. and Sparks, R.S.: The LyonBeutler hypothesis and isochromosome $\mathrm{X}$ patients with Turner's syndrome. Lancet $i i: 411$ (1963).

9. Hayfurck, L. and Moorhead, P.S.: The serial cultivation of human diploid cell strains. Exp. Cell Res. 25: 585-621 (1961).

10. Hungerford, D.A.: Leukocytes cultured from small inocula of whole blood and the preparation of metaphase chromosomes by treatment with hypotonic KCl. Stain Technol. 40: 333-338 (1965).

11. Maxall, B.H.: The detection of small differences in DNA content with microspectrophotometric techniques. J. Gell Biol. 31: 74A (1966).

12. Mendelsohn, M.L.; Mayall, B.H.; Prewitt, J.M.S.; Bostrom, R.C. and Holcomb, W.G.: Digital transformation and computer analysis of microscopic images; in: Advances in optical and electron microscopy (Academic Press, New York, in press).

13. Morishima, A.; Grumbach, M. M. and Taylor, J.H.: Asynchronous duplication of human chro mosomes and the origin of sex chromatin. Proc. nat. Acad. Sci. (Wash.) 48: 756-763 (1962).
14. Müntzing, A.: The evolutionary significance of autopolyploidy. Hereditas (Lund) 21: 263-378 (1936).

15. Root, A.W.; Rosenfield, R.L.; Bongrovanni, A.M. and Eberlein, W.R.: The plasma growth hormone response to insulin-induced hypoglycemia in children with retardation of growth. Pediatrics 39: 844 (1967).

16. TJro, J.H. and Whang, J.: Chromosome preparations of bone marrow cells without prior in vitro culture or in vitro colchicine administration. Stain Technol. 37: 17-20 (1962).

17. We express our gratitude to Dr. F.H.Allen, Jr., for blood groupings, Dr. L.HAYFLICK for certain cell cultures, Dr. M.L. MendeLsohn for advice, Dr. F.A. Oski for hematological consultation, and Dr. W.C. Yakovac for the pathology report.

18. This work was supported by USPHS Grants HD00588, HD-05545, FR-00240, 5T1-AI-154, and USPHS Contract No. PH 43-62-432.

19. Kohn, Gertrude, M.D., The Children's Hospital of Philadelphia, 1740 Bainbridge Street, Philadelphia, Pa. 19146 (USA). 